\section{Power relations and the public health challenge}

\author{
Ruth E Malone
}

The disease, suffering and premature death caused by tobacco products are unevenly distributed. This is at least partly because smoking prevalence in many countries, particularly those at later stages of the tobacco epidemic, is much higher among marginalised groups: minority groups who experience various forms of discrimination; people who are financially deprived; those who are mentally ill; and those in prisons and jails, among others. However, these same groups, compared with those who are relatively more advantaged and powerful in society, may also experience other forms of health injustice - more targeted marketing of deadly products, reduced access to preventive health services, communities with more environmental toxins, crime, stress, and fewer economic opportunities. Tobacco is a social justice issue, and the papers in this special collection help draw attention to that fact and call on each of us to acknowledge the ways in which our power (or lack thereof) shapes our health status.

Curry et al ${ }^{1}$ document the phenomenon of e-cigarettes made especially for inmates of prisons and jails, a population with extraordinarily high tobacco use rates who too often are forgotten in public health initiatives. While many institutions now have smokefree policies to protect the health of nonsmoking inmates, e-cigarettes could alter the landscape in unknown ways. Some claim their availability increases morale and decreases contraband issues. However, it is still unknown if there are any long-term effects from e-cigarette use on nonusers in enclosed institutional settings. The fact that this population is challenging to study should not be an excuse to allow them to be exposed as captives to potential new risks without assessing possible effects on health.

In an important review, Hill et $a l^{2}$ analyse the socioeconomic impact of six tobacco control interventions: price increases, smokefree policies, ad bans, mass media campaigns, warning labels, and smoking cessation support, plus multifaceted community based programmes

Correspondence to Professor Ruth E Malone, Department of Social and Behavioral Sciences, School of Nursing, University of California, San Francisco, San Francisco, CA 94118, USA; ruth.malone@ucsf.edu combining approaches. Their review shows that increases in tobacco price have a pro-equity effect on socioeconomic disparities in tobacco use; other approaches, while effective overall, may worsen disparities as people in higher income groups are more responsive to these measures. The review highlights the tension between reducing tobacco use on a population level and reducing tobacco-related health disparities among groups. A second review in this issue analyses the 'equity impact' of interventions to reduce smoking in youth, examining multiple measures. ${ }^{3}$ Again, price increases were found to have the most effect, suggesting that among the armamentarium of public health measures known to reduce tobacco use, increasing tobacco taxes and prices should perhaps be first priority from a social justice perspective.

Blakely et al's ${ }^{4}$ work suggests, however, that the story may be more nuanced than that. It would be a mistake to assume that in all cases worsening deprivation is associated with higher rates of tobacco use. In an innovative repeated measures panel study, they explored changes in smoking behaviour associated with changes in social position determinants and found that decreasing income seems to have little effect on number of cigarettes smoked, but increasing income increases the odds of smoking among young people, likely due to the initiation effect. Understanding better how short-term versus long-term changes in social circumstances affect tobacco use will be important in sorting out how to evaluate the impact of various equity-focused programmes.

Continuing the exploration of equity as a tobacco control issue, Dutra et $a l^{5}$ examined experiences of racial and nonracial discrimination among South African adults, adding to an extensive literature suggestive that discrimination increases risk of smoking. While the study is limited by its cross-sectional design, it raises interesting questions in trying to tease out distinctions between racial and nonracial and acute versus chronic experiences of discrimination.

Stoklosa and Ross $^{6}$ call attention to another aspect of equity in global tobacco control: funding streams. They updated a database compiling information on development assistance funding for tobacco control and demonstrated that funding has declined significantly from the 2000 to 2009 trend. Further, they note that the funding sources are fewer, and call for attention to the fact that as developed countries have begun envisioning an endgame for the tobacco epidemic, low and middle income countries are left with erratic, inadequate sources of funding that are vulnerable to shifts in the priorities of a few wealthy individuals and foundations. They discuss innovative funding mechanisms that might help address this gap. To do otherwise, this work suggests, is to leave the epidemic to the countries least-resourced to cope with it.

After decades of exclusion from national surveys, many countries now collect health data on lesbian, gay, and other sexual minority populations, and such data show that these groups tend to have higher tobacco use rates than the general population. Hatzenbuehler $e t \quad a l^{7}$ take up the important topic of how state-level tobacco environment affects tobacco use rates. Sexual orientation disparities were lower, and likelihood of ever smoking lower, in states with stronger tobacco control environments. While other factors besides tobacco control policy may contribute to these findings, there is still much to learn about how to reduce smoking among lesbian gay bisexual and transgender (LGBT) communities. A study by Lee et $a l^{8}$ is perhaps the first to examine tobacco imagery in movies with LGBT themes and characters. Lee found that viewers of such films were exposed to 1 depiction of smoking for every $15 \mathrm{~min}$ of run time, consistent with previous studies suggesting that tobacco images are normative in LGBT-targeted media. In turn, this suggests that efforts to reduce tobacco use in these communities may require targeted denormalisation efforts such as some of those featured here: http://www. lgbttobacco.org/resources.php?ID =24\#35

While there remains contention over the idea that as the tobacco epidemic winds down, the remaining smokers are 'hardcore' and resistant to quitting, Clare et $a l,{ }^{9}$ using four waves of Australian national survey data, found that overall, so-called 'hardcore' smoking remained stable. However, they also found that 'hardcore' smoking declined among highsocioeconomic status (SES) smokers, but not among low-SES individuals. They conclude that 'hardcore' smokers can indeed quit successfully, but that not enough is known about what factors associated with higher SES help them do so in 
greater numbers than individuals with lower SES.

It is, as other studies have shown, no accident that smoking rates are higher among low SES populations. Ling and her colleagues describe the multiple ways in which tobacco companies focused intense cigarette marketing efforts on low SES women, including psychographic profiling aimed at exploiting social-psychological vulnerabilities among subgroups. ${ }^{10}$ While this study was focused on the USA, similar approaches to targeting women have been documented in other countries.

Previous research has suggested that smoking rates are also higher among individuals with mental illness. McKee and colleagues $^{11}$ analysed a two-wave cohort survey of a nationally (US) representative sample of non-institutionalised adults and demonstrated that those with any current psychiatric diagnosis had three times the odds of current smoking than those without such a diagnosis; cessation rates were also lower among those with psychiatric illness.

Finally, there is evidence that menthol in cigarettes increases experimentation and progression to regular smoking, and that especially among African Americans, this may make it harder to quit smoking. The paper by Delnevo et al ${ }^{12}$ demonstrates that in the US, the decline in cigarette consumption has been greatest among non-menthol cigarettes. In the context of impending US Food and Drug Administration regulation of menthol in cigarettes, this important work shows that menthol cigarettes are indeed different than non-menthol cigarettes. Since the vast majority of African American smokers use menthol, this work adds to a substantial body of evidence suggesting that effective regulation of cigarettes at the population level, using a public health standard, will require addressing menthol.

Taken as a whole, this collection of work reminds us that health is directly related to power, and thus this research ought to prompt each of us to ask ourselves in what ways we are seeking to address the power gaps that face marginalised groups and communities. How have we engaged these groups and communities in our efforts? When have we invited speakers from these communities to address our strategic planning meetings, and paid for them to attend? How have we sought to learn from them what might work better than what we are doing across the board? Have we considered involving them as research partners, allowing them to develop the research questions that are most relevant to their communities?

As we move toward planning an end to the tobacco epidemic, we must find new ways to be 'better together' by partnering with those communities that are hardest-hit by the suffering tobacco products cause. It's hard to do, and many tobacco control leaders simply don't know how to do it. The very first step is cultivating the humility to reach out and admit we don't have all the answers.

Acknowledgements Thanks to Dr Valerie Yerger for helpful comments on this editorial.

Competing interests None.

Provenance and peer review Not commissioned; internally peer reviewed.

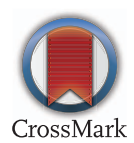

To cite Malone RE. Tob Control 2014;23:e85-e86.

Tob Control 2014:23:e85-e86.

doi:10.1136/tobaccocontrol-2014-052087

\section{REFERENCES}

1 Curry L, Ok Lee Y, Rogers T. E-cigarettes made especially for inmates. Tob Control 2014;23:e87-8.

2 Hill $S, A$ mos A, Clifford D, et al. Impact of tobacco control interventions on socioeconomic inequalities in smoking: review of the evidence. Tob Control 2014;23:e89-97.

3 Brown T, Platt $S$, Amos A. Equity impact of interventions and policies to reduce smoking in youth: systematic review. Tob Control 2014;23: e98-105.

4 Blakely T, van der Deen FS, Woodward A, et al. Do changes in income, deprivation, labour force status and family status influence smoking behaviour over the short run? Panel study of 15,000 adults. Tob Control 2014;23:e106-13.

5 Dutra LM, Williams DR, Kawachi I, et al. Racial and non-racial discrimination and smoking status among South African adults 10 years after apartheid. Tob Control 2014;23:e114-21.

6 Stoklosa M, Ross H. Tobacco control funding for low-income and middle-income countries in a time of economic hardship. Tob Control 2014;23:e122-6.

7 Hatzenbuehler ML, Keyes KM, Hamilton A, et al. State-level tobacco environments and sexual orientation disparities in tobacco use and dependence in the USA. Tob Control 2014;23: e127-32.

8 Lee JGL, Agnew-Brune CB, Clapp JA, et al. Out smoking on the big screen: tobacco use in LGBT movies, 2000-2011. Tob Control 2014;23:e156-8.

9 Clare P, Bradford D, Courtney RJ, et al. The relationship between socioeconomic status and 'hardcore' smoking over time-greater accumulation of hardened smokers in low-SES than high-SES smokers. Tob Control 2014;23:e133-8.

10 Brown-Johnson CG, England LJ, Glantz SA, et al. Tobacco industry marketing to low socioeconomic status women in the USA. Tob Control 2014;23: e139-46.

11 Smith PH, Mazure CM, McKee SA. Smoking and mental illness in the US population. Tob Control 2014;23:e147-53.

12 Delnevo CD, Villanti AC, Giovino GA. Trends in menthol and non-menthol cigarette consumption in the USA: 2000-2011. Tob Control 2014;23:e154-5. 